\title{
Disability-adjusted life years lost due to diabetes in France, Italy, Germany, Spain, and the United Kingdom: a burden of illness study
}

This article was published in the following Dove Press journal:

ClinicoEconomics and Outcomes Research

23 March 2015

Number of times this article has been viewed

\section{Josep Darbà' \\ Lisette Kaskens ${ }^{2}$ \\ Bruno Detournay ${ }^{3}$ \\ Werner Kern ${ }^{4}$ \\ Antonio Nicolucci ${ }^{5}$ \\ Domingo Orozco-Beltrán ${ }^{6}$ \\ Antonio Ramírez de \\ Arellano $^{7}$}

'Department of Economics, University of Barcelona, Barcelona, Spain;

${ }^{2}$ Department of Health Economics, BCN Health Economics and

Outcomes Research SL, Barcelona,

Spain; ${ }^{3}$ Department of Health

Economics, CEMKA-EVAL, Bourg-la-

Reine, France; ${ }^{4}$ Department of

Endocrinology, Endokrinologikum,

Center for Hormone and Metabolism,

Ulm, Germany; ${ }^{5}$ Department of

Endocrinology, Mario Negri Sud

Foundation, Santa Maria Imbaro, Italy;

${ }^{6}$ Department of Family Medicine,

University Miguel Hernández, Alicante,

Spain; ${ }^{7}$ Department of Health

Economics, EU-HEOR Novo Nordisk, Madrid, Spain
Correspondence: Josep Darbà Department of Economics, Universitat de Barcelona, Diagonal 690, Barcelona, Spain Tel +34934020 I I0; +3493402। 937

Fax +34934039082

Email darba@ub.edu
Aims: To compare the burden of disease (BoD) attributable to diabetes expressed in disabilityadjusted life years (DALYs) for five European countries in 2010.

Methods: DALYs lost to diabetes as the sum of years of life lost and years lived with disability were estimated by sex and age using country-specific epidemiological data and global disability weights. Data from various secondary sources were combined to estimate health loss due to diabetes for France, Germany, Italy, Spain, and the UK. National statistical databases were used and if necessary, community studies were used to derive the prevalence of diabetes by sex and age group, which were weighted proportionately for a national population burden of disease estimate. All identified data were adapted to the Global Burden of Disease methodology (2010) to calculate the burden attributable to diabetes. No age weighting and discounting was applied. Sensitivity to different sources of variation was examined. Germany and Italy lost the largest number of DALYs due to diabetes, with 5.9 and 5.8 per 1,000 inhabitants, respectively, followed by Spain (4.4), France (3.7), and the UK (2.9). The highest burden was caused by mortality due to diabetes, with the exception of the UK, for which the burden due to disability of diabetes was higher. Mean DALYs lost were higher for women in Germany, Italy, and Spain and shown to increase with age for all countries. Sensitivity analysis in variation in disability weights and uncertainty in epidemiological data were shown to have effects on DALYs lost.

Conclusion: In spite of data limitations, the estimates reported here show that DALY loss due to diabetes imposes a substantial burden on countries. Cross-national variation in disease epidemiology was the largest source of variation in the burden of diabetes between countries. Keywords: prevalence, mortality, life expectancy, DALY

\section{Introduction}

Diabetes mellitus is a group of metabolic diseases characterized by hyperglycemia resulting from defects in insulin secretion, insulin action, or both. There are three major types of diabetes: type 1 diabetes, type 2 diabetes, and gestational diabetes. The most prevalent are type 1 and 2 .

Type 1 diabetes mellitus (T1DM) is produced by the destruction of $\beta$ cells of the pancreas. This leads to insulin deficiency, which can be mild initially, but develops quickly towards a complete lack of the hormone. The process is generally rapid in infants and children and slow in adults. The velocity of $\beta$-cells destruction is variable and in case of infants it usually progresses rapidly while this loss is somewhat slower in case of adults. A predisposition to develop T1DM is passed through generations in families, but the inheritance pattern is unknown. Moreover, there are also environmental factors related to the probability of developing T1DM that are still unclear. This type of diabetes accounts for $5 \%-10 \%$ of those diabetics. Generally, people 
with T1DM present with acute symptoms of diabetes and markedly elevated blood glucose levels. ${ }^{1}$

The pathophysiology of type 2 diabetes mellitus (T2DM) combines defects that lead finally to hyperglycemia. First of all, there is insulin resistance produced in the striated muscle (also called peripheral insulin) and insulin resistance produced in the liver (also called central insulin resistance). These stimulate the production of insulin in the $\beta$ cells. However, since the cells fail to maintain sufficient hormone quantity to offset insulin resistance, hyperglycemia arises, which indicates failure in insulin secretion. This form of diabetes accounts for $90 \%-95 \%$ of those patients with diabetes, but many cases remain underdiagnosed until complications appear. At the mild stage, controlling diabetes symptoms by making changes in the lifestyle is possible. However, as this type of diabetes is progressive and chronic, it requires more intensive therapy as the disease progresses. Eventually, patients need to take medication to keep blood glucose at normal levels. ${ }^{1}$

Diabetes mellitus is a worldwide problem, which accounted for 1.3 million lives in $2008 .^{2}$ This chronic illness requires continuing medical care and patient self-management education. In addition to the consequences of abnormal glucose metabolism, diabetes mellitus can lead to long-term complications (cardiovascular, peripheral vascular, ocular, neurologic, and renal). ${ }^{3,4}$ In Europe, there are about 60 million people with diabetes, approximately $10.3 \%$ of men and $9.6 \%$ of women aged 25 years and over. Across countries, Germany, Spain, and Italy were respectively on the second, fourth, and fifth position regarding the highest numbers of people with diabetes in Europe in $2013 .{ }^{5}$ Diabetes mellitus has been shown to be an expensive condition, costing the European Union over $€ 50$ billion per year. ${ }^{6,7}$

The impact of diabetes can be measured by using the concept of burden of disease (BoD), which is used to assess and compare the relative burden of different conditions by quantifying health loss due to the disease and injury that remains after treatment, rehabilitation, or prevention efforts of the health system and society in general. ${ }^{8}$ The BoD can be measured by cost, morbidity, and mortality. In the last few decades, this burden has been increasingly measured across nations for comparability purposes. ${ }^{9-12}$ Disability-adjusted life years (DALYs) ${ }^{13}$ are a measure that combines the concept of potential years of life lost due to premature death and years of 'healthy' life lost in states of less than full health (disability states) $;{ }^{14}$ hence, DALYs reflect the burden of a condition and facilitate comparisons of different (in theory all) types of health conditions or health outcomes. In particular, DALYs may be used to include the burden caused by disability and chronic diseases in cost-effectiveness studies. ${ }^{15}$ Compared to quality-adjusted life years (QALYs), DALYs permit comparisons across different interventions or health areas to understand the effectiveness of a portfolio of interventions by using a standardized set of disability weights. ${ }^{16}$

The objective of this study was to carry out a literature review to collect data on epidemiology, life expectancy (LE), mortality, quality of life (QoL), and disability for DALY calculation on diabetes for France, Germany, Italy, Spain, and the UK. The data were used to calculate the number of DALYs for the total patient population with diabetes for the countries of interested by sex and age group and to compare between countries for 2010 .

\section{Materials and methods}

This study used DALYs as a measure of the burden of the disease. The DALY is a health gap measure that combines information on fatal and nonfatal health outcomes; hence, the DALY measures the health loss. The basic assumption of DALYs is that similar events would be treated equally in all populations to ensure comparability; hence, individual characteristics are restricted to age and sex.

This research used the hybrid DALY (H-DALY) approach to calculate the DALYs for comparisons. ${ }^{17,18} \mathrm{H}$-DALYs are calculated by adding incidence of years of life lost (YLLs) to prevalence of years lived with disability (YLDs), and thus quantifies both the BoD occurring during the reference period and the burden accrued into the future. The hybrid method is a true period-measure because all the data needed to calculate H-DALYs can be measured in the time period.

The YLL is the number of years that death occurred earlier than the age the person was expected to die if he/she had not suffered from the disorder causing death. YLL was calculated as follows:

$$
\mathrm{YLL}=\mathrm{D}_{\mathrm{e}} \times \mathrm{L}
$$

with $\mathrm{D}_{\mathrm{e}}$ being the number of deaths related to diabetes as the primary cause in a certain time period and $\mathrm{L}$ being the residual LE at each year of age ${ }^{8}$ (standard LE when being in a certain age category). YLLs were calculated per country, age range, and sex.

The YLD is the number of years due to disability and is calculated by multiplying the years lost with a disability weight reflecting the severity of the condition. YLD is calculated as follows:

$$
\mathrm{YLD}_{\text {prevx }}=\mathrm{P}_{\mathrm{x}} \times \mathrm{Dw}_{\mathrm{x}}
$$


with $\mathrm{P}_{\mathrm{x}}$ being the prevalent cases and $\mathrm{Dw}_{\mathrm{x}}$ being the disability weight. From the prevalence and the population data, the prevalent cases with diabetes per age category are calculated as the outcome of prevalence multiplied by population (total), which are calculated per country, age group, and sex.

Then, the DALY formula is as follows:

$$
\mathrm{DALYs}=\mathrm{YLDs}_{\mathrm{prevx}}+\mathrm{YLLs}
$$

In this study, since the incidence of diabetes was not available to calculate the YLDs component of the DALY, an incidence-based method was not feasible. Nonetheless, the data available on prevalence for diabetes of different age categories were available for France, Germany, Italy, Spain, and the UK. Moreover, the discounting process is not applicable in this context since this study is a static picture of the burden of diabetes in 2010. Finally, no age-weighting factor was applied to DALYs, which is similar to the last version of the global BoD by Murray et al, which also did not apply any age weights. ${ }^{19}$

The H-DALY avoids both the polio and Elvis problems. The polio problem refers to the fact that the incidence is captured at a certain point in time and if there are no new cases in the next year, the burden might be underestimated. The Elvis problem refers to the counterfactual assessment that overestimates the prevalence since some cases could be diagnosed many years ago.

Moreover, only YLLs were calculated from an incidence perspective, which makes it easy to choose death as the event and connect all YLLs to the moment of death. The hybrid methods consistently combine the projection of the future duration of disability (incidence part) and the knowledge of deaths that occurred prior to the time period in question (prevalence part).

\section{Input data}

The demographic data on the population size specified by age and gender were collected for every country from each national statistics database. ${ }^{20-24}$ Similar to population size data, LE (which is not related to any specific disease) by age group, and sex were collected for the five countries from their national statistics. The epidemiological data with reference to prevalence were obtained from each national statistics database, except for France (Ricci et al) ${ }^{25}$ and Germany (Heidemann et al). ${ }^{26}$ Prevalence data for the UK included region-specific data for England, ${ }^{27}$ Scotland, ${ }^{28}$ Wales, ${ }^{29}$ and Northern Ireland..$^{30}$ To be able to compare the UK with other countries of interest, uniform age categories for the communities within the UK were defined. For the age group 0-14 years, prevalence data only included T1DM, as no data on type 2 diabetes for this age category were available. It is assumed that $97 \%$ of the population in this age group was suffering from T1DM. The prevalence data were equal for boys and girls.

The demographic data on deaths caused by diabetes from France, ${ }^{31}$ Germany, ${ }^{32}$ Italy ${ }^{33}$ Spain, ${ }^{34}$ and the UK ${ }^{35}$ were obtained. Diabetes mortality rates were obtained by using the number of deaths due to diabetes relative to the total population. Figures 1 and 2 contain estimations of mortality due to diabetes for men and women, respectively. In case of men's mortality, there is an increasing pattern from age range 55-64 years onwards. Differences across countries are clear: the UK had the lowest mortality rate while France is the second best-off; the mortality rates for France were two times higher than the UK rates. At the age range $75+$ years, Germany and Spain had very similar mortality rates. By far the highest value was for Italy, where more than 250 out of 100,000 men aged 75 years and over died from diabetes in 2010 .

For women (Figure 2), diabetes mortality was quite low for the younger age ranges but there was a steep increment from 65-74 years to the 75+ years age range for France, Germany, Italy and Spain. For instance in Italy, the mortality rate went from 40 to 263 per 100,000 women.

These rates were used to obtain the YLL by using the average age of death per age group and LE for every age group. The full formula used for YLL calculation was derived from the World Health Organization (WHO) and Fox-Rushby and Hanson. ${ }^{10,12}$

Furthermore, for this study, the disability weights for the treated population were 0.033 . It is assumed that $2.4 \%$ of the adult population 15 years old and over are not treated for their diabetes based on estimates by Hill et al; The disability weight applied for untreated diabetics was $0.012 .{ }^{36}$ These disability weights were obtained from the Global BoD study. ${ }^{9}$ For children between $0-14$ years old, it is assumed that this population was $100 \%$ treated since they almost always uniquely suffer from T1DM. For the sensitivity analysis, a disability weight of 0.07 was used for YLD calculation based on Stouthard et al and Mathers et al..$^{37,38}$

\section{Results}

Detailed results of YLL, YLD, and DALY for 2010 are presented in Table 1. Estimates for France, Germany, Italy, Spain, and the UK were calculated as a rate per 1,000 inhabitants (inh) in order to compare results between countries. 


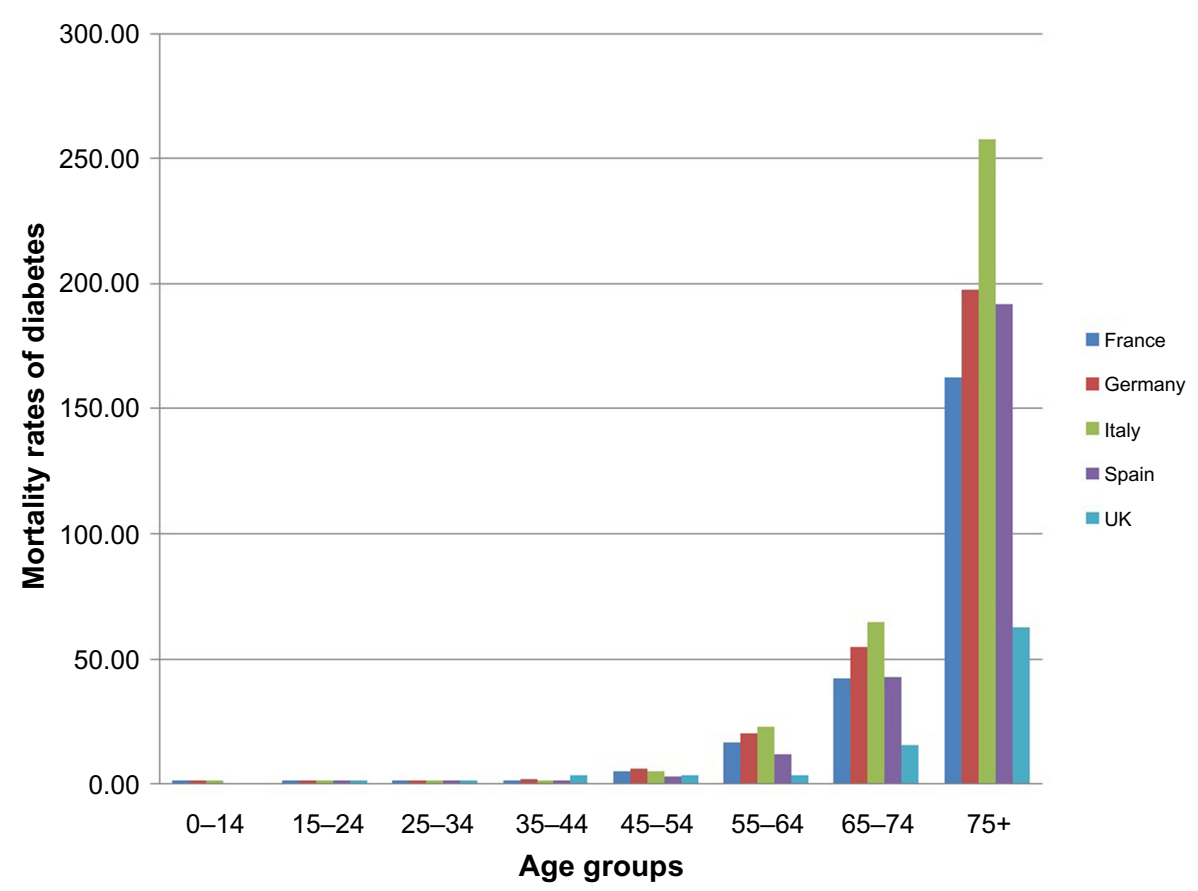

Figure I Male mortality rates by age group in 2010.

Overall, the relative burden of diabetes was shown to be the highest for Germany and Italy: their estimates were 5.9 and 5.8 DALYs per 1,000 inh, respectively. On the contrary, the UK had the lowest value of total DALYs lost, at 2.94 DALYs per 1,000 inh. In between these extremes, the negative impact of diabetes in France and Spain caused 3.70 and 4.36 DALYs per 1,000 inh, respectively.

As has been mentioned, each component of the DALY reflects the health losses associated with diabetes. The YLD captures the decrease in full health and reflects the degree of disability. The YLL is the difference between the expected age at death (LE) and actual age at death (mortality due to diabetes). Differences between components of DALYs across countries can also be seen in Table 1. Regardless of sex, estimates of YLL were greater than YLD for France, Germany, Italy, and Spain; in contrast, YLDs were greater than YLLs for the UK. The differences were driven by the values of YLL for both sexes. For instance, for men, although YLDs values

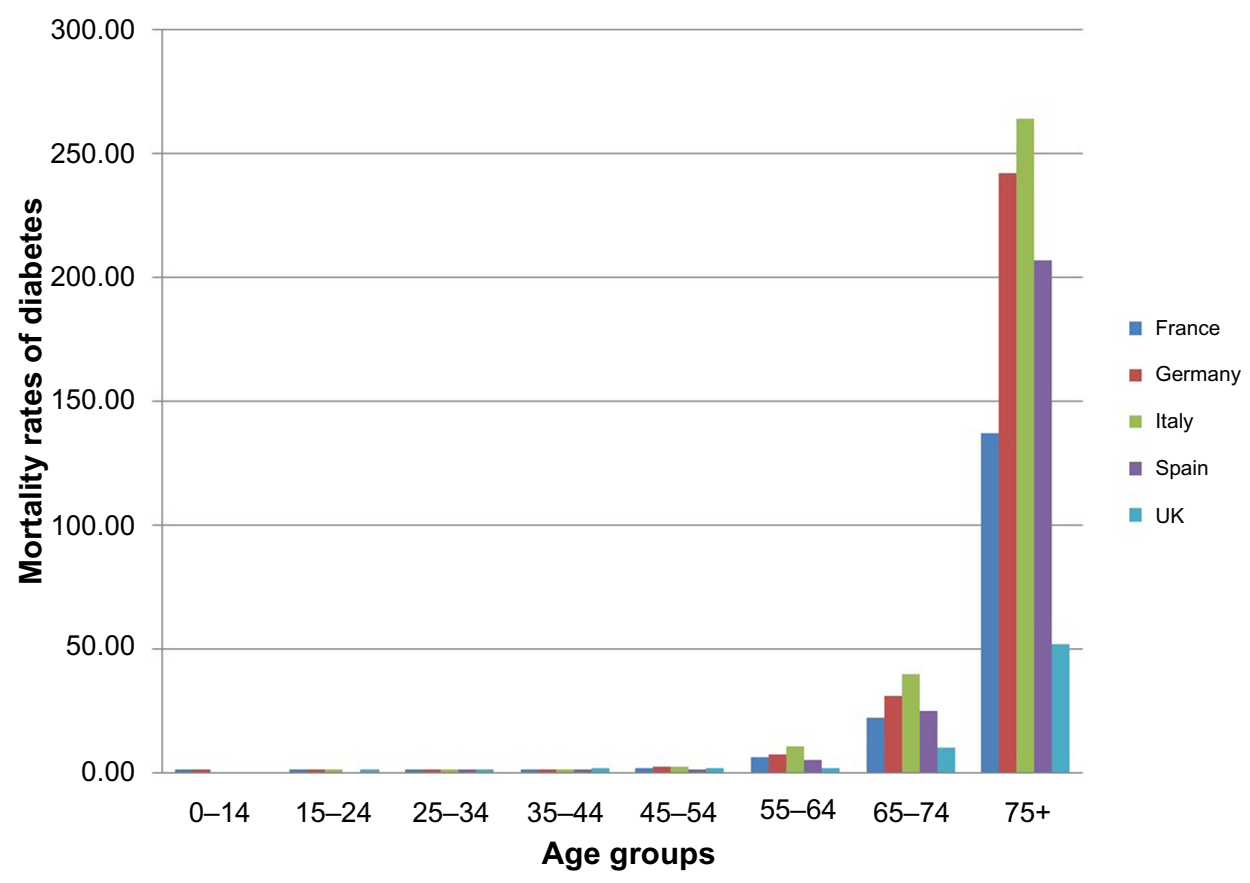

Figure 2 Female mortality rates by age group in 2010 . 
Table I YLLs (men and women), YLDs (men and women), and DALYs lost (men, women, and total) due to diabetes in the five EU countries of interest including inhabitants of all ages in 2010

\begin{tabular}{|c|c|c|c|c|c|c|c|}
\hline & $\begin{array}{l}\text { YLL } \\
\text { men }\end{array}$ & $\begin{array}{l}\text { YLL } \\
\text { women }\end{array}$ & $\begin{array}{l}\text { YLD } \\
\text { men }\end{array}$ & $\begin{array}{l}\text { YLD } \\
\text { women }\end{array}$ & $\begin{array}{l}\text { DALYs lost } \\
\text { men }\end{array}$ & $\begin{array}{l}\text { DALYs lost } \\
\text { women }\end{array}$ & $\begin{array}{l}\text { Total } \\
\text { DALYs lost }\end{array}$ \\
\hline France & 2.20 & 2.32 & 1.59 & 1.29 & 3.80 & 3.61 & 3.70 \\
\hline Germany & 3.02 & 3.64 & 2.35 & 2.64 & 5.37 & 6.28 & 5.83 \\
\hline Italy & 3.57 & 4.58 & I.73 & I.78 & 5.30 & 6.35 & 5.84 \\
\hline Spain & 2.09 & 2.88 & 1.89 & 1.86 & 3.98 & 4.74 & 4.36 \\
\hline UK & 1.08 & 0.97 & 2.08 & $\mathrm{I} .74$ & 3.17 & 2.71 & 2.93 \\
\hline
\end{tabular}

Notes: Disability weights for treated and untreated are 0.07. YLL, YLD, and DALY are per I,000 inhabitants.

Abbreviations: DALYs, disability-adjusted life years; EU, European Union; YLDs, years lived with disability; YLLs, years of life lost.

could be considered that follow a similar pattern, the UK has one-third of Germany's YLL. Indeed, the difference between the highest and the lowest YLD was 0.49 , while the disparity in YLL values was 2.49 points. This suggests that there is a higher burden caused by mortality due to diabetes for France, Germany, Italy, and Spain, whereas in the UK, the burden due to disability was higher.

The last three columns contain DALYs for countries of interest for women and men. The smallest value of DALY was seen for women in the UK. Differences in DALY values indicate that the burden of diabetes was higher for women compared to men in Germany, Italy, and Spain in 2010. For instance, Italian diabetic women lost one DALY more than Italian diabetic men. Conversely, DALYs in France and the UK were higher for men, suggesting a higher burden of diabetes for men compared to women in these two countries of interest.

The total number of DALYs per age group for men and women are shown in Figures 3 and 4, respectively.
Diabetes DALYs lost for men were very low for the younger age ranges, for all countries. However, in the UK, for those aged 35-44 years, the burden increased substantially, while diabetes DALYs remained low for the rest of these countries of interest. Diabetes was shown to consistently increase the burden of the disease across all age groups in France, Germany, Italy, and Spain with the exception of the UK, whose burden did not start to expand again until the 55-64 years age group upwards (Figure 3).

Diabetes DALYs for women were very low for the younger age ranges in 2010 (Figure 4). The impact of diabetes continued quite constantly until the 45-54 years age group, after which diabetes burden became notable. Although increments of DALYs lost for the 45-54 and 65-74 years age groups were modest, diabetes burden increased heavily in the older age groups, for all five countries.

For all five countries, DALYs due to diabetes of the elderly population (65-74 and 75+ years) were divergent across countries for both men and women, which suggests

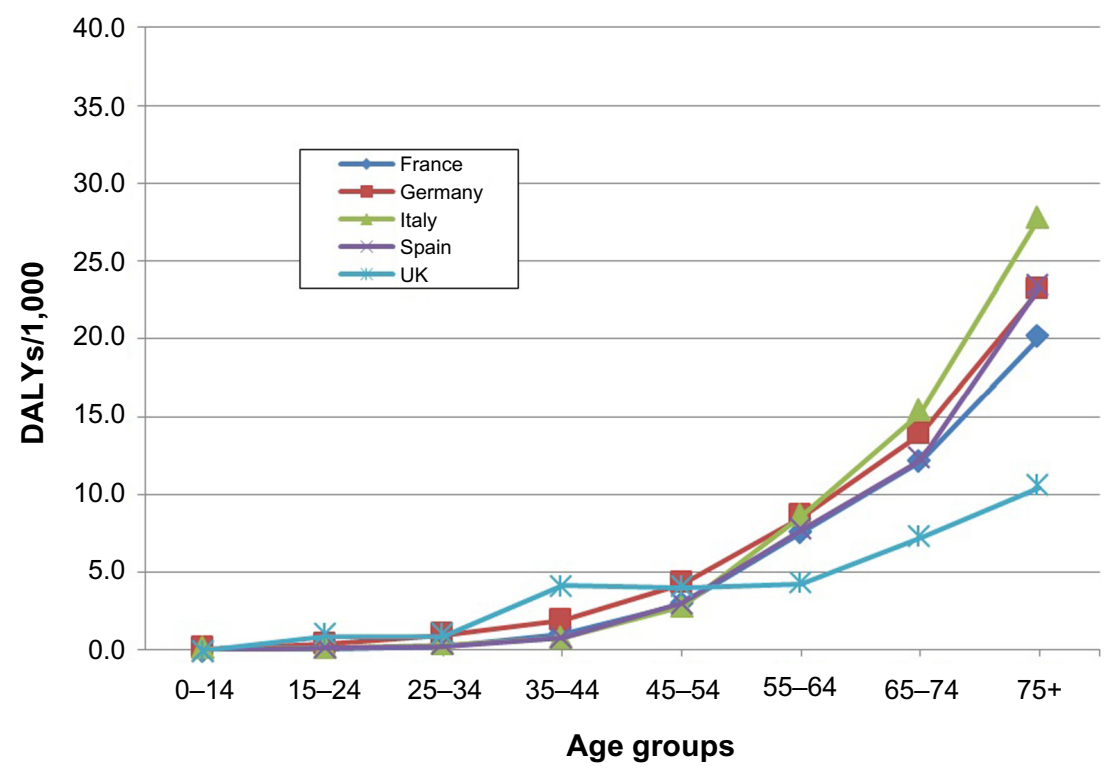

Figure 3 DALY losses due to diabetes per I,000 men by age. Abbreviation: DALYs, disability-adjusted life years. 


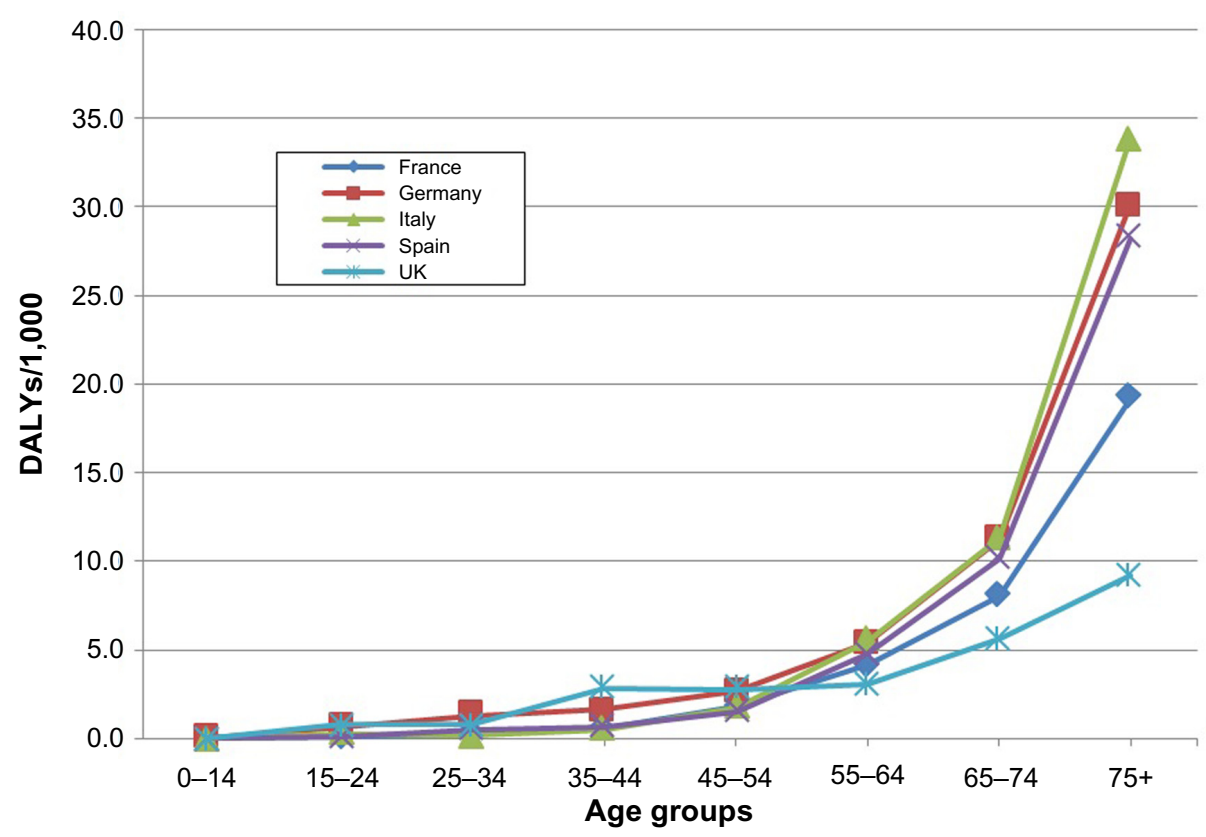

Figure 4 DALYs due to diabetes per I,000 women by age (2010).

Abbreviation: DALYs, disability-adjusted life years.

that burden of the disease is quite different across countries for the oldest groups. Indeed, the UK's values were almost one-third of the DALYs in Germany. The increasing number of DALYs along with older ages might be explained due to the increasing prevalence and mortality of diabetes in older age groups (Figures 1 and 2). Thus, it is straightforward to distinguish different patterns: Italy, Germany, and Spain had a steep increment in diabetes burden as age increases, while the UK was shown to have the mildest burden, and France was in between the two trends.

\section{Sensitivity analysis of disability weights}

In the sensitivity analysis, the disability weight used was 0.07 for the treated and untreated diabetics; ${ }^{25}$ the results are shown in Table 2. This value represents a higher severity of diabetes compared to previous disability weights. This fact is reflected in the DALYs estimates: the loss of DALYs due to diabetes was higher for all countries in comparison with the base case. Germany has the largest DALY lost and the UK has the smallest lost. The ranking is unaltered: Germany has the highest DALY loss, Italy is the second worse-off, the third position was held by Spain, and the fourth and fifth positions were held by France and the UK, respectively. Despite the unaltered burden ranking, Germany also has the biggest difference if we compared estimates of the sensitivity analysis and the base case (2.87 DALY per 1,000 inh). The second biggest difference was for the UK, which had 2.17 DALYs extra per 1,000 inh. The smallest difference was for France, with a difference of only 1.6 DALY lost per 1,000 inh.

\section{Discussion}

The present study provides a reliable image of the burden of diabetes for France, Germany, Italy, Spain, and the UK in 2010 according to the methodology by the WHO. ${ }^{19,20}$ We provide estimates on diabetes itself, not based on the comorbidities due to diabetes. The approach used presents a broad insight of the burden of this condition because it makes comparison between countries feasible.

Table 2 Sensitivity analysis results

\begin{tabular}{|c|c|c|c|c|c|c|c|}
\hline & $\begin{array}{l}\text { YLL } \\
\text { men }\end{array}$ & $\begin{array}{l}\text { YLD } \\
\text { men }\end{array}$ & $\begin{array}{l}\text { YLL } \\
\text { women }\end{array}$ & $\begin{array}{l}\text { YLD } \\
\text { women }\end{array}$ & $\begin{array}{l}\text { DALYs lost } \\
\text { men }\end{array}$ & $\begin{array}{l}\text { DALYs lost } \\
\text { women }\end{array}$ & $\begin{array}{l}\text { Total } \\
\text { DALYs lost }\end{array}$ \\
\hline France & 2.20 & 3.38 & 2.32 & 2.73 & 5.59 & 5.05 & 5.32 \\
\hline Germany & 3.02 & 5.07 & 3.64 & 5.68 & 8.09 & 9.32 & 8.70 \\
\hline Italy & 3.57 & 3.73 & 4.58 & 3.82 & 7.30 & 8.40 & 7.90 \\
\hline Spain & 2.09 & 4.07 & 2.88 & 4.00 & 6.15 & 6.88 & 6.50 \\
\hline UK & 1.08 & 4.49 & 0.97 & 3.75 & 5.57 & 4.72 & 5.10 \\
\hline
\end{tabular}

Note: YLL, YLD, and DALY are per I,000 inhabitants.

Abbreviations: DALYs, disability-adjusted life years; YLDs, years lived with disability; YLLs, years of life lost. 
Using the H-DALY method, with incidence YLLs and prevalence YLDs, DALYs due to diabetes were the highest in Germany and the lowest in the UK. The major part of the burden was caused by premature mortality in France, Germany, Italy, and Spain. However, disability due to diabetes was shown to be the primary contributor to the burden for the UK. A possible explanation for the lowest DALY due to diabetes in the UK could be that the age-specific mortality has been decreasing, with considerably fewer numbers of deaths due to diabetes from the age of 65 years in men and women compared to the mortality rates of the other countries of interest. Further, given that YLDs are quite similar across countries, the results suggest that diabetes is better managed in the UK, avoiding fatal events associated with this condition. Given these results, to determine in which country the burden of diabetes was the largest, DALYs seemed necessary since the burden is not mainly driven by epidemiological frequency (mortality).

Additionally, it was possible to compare the burden of diabetes in men and women. Estimates showed that the burden of diabetes is higher in men compared to women. Overall, men had a higher number of DALYs $(46.46$ per 1,000$)$ compared to women $(35.52$ per 1,000$)$ despite the steep increase in the number of DALYs in women from 75+ years.

Regarding the methodological aspects, H-DALYs have the advantage of avoiding both the polio and Elvis problems, and only YLLs were calculated from an incidence perspective, which makes it easy to choose death as the event and connect all YLLs to the moment of death. ${ }^{20}$ All the data needed to calculate H-DALYs can be measured at the time in question, so these DALYs are a true period measure.

There are limitations to these estimates. Firstly, the availability of input data conditioned our analysis. Prevalence data were not directly available for all districts from one national statistics database in the UK. Therefore, prevalence data were taken from different sources and adjusted to the relevant age categories. In case prevalence information was missing for an age category, it was estimated based on the mean prevalence of an equivalent age category from another country of interest.

Secondly, disability weights were equal for all age categories and for both sexes as no direct $\mathrm{QoL}$ data were available to obtain individual disability weights that could have affected YLDs. In general, diabetes might be perceived differently at different ages ${ }^{39}$ which could vary the estimates. Therefore, either different disability weights should be applied for each age range or age weighting should be introduced. Both alternatives are controversial, and so far, there is no agreement of consistent estimates of potential weights (Murray and
Acharya, 1996; Anand and Hanson, 1997). Moreover, in this study, a sensitivity analysis was performed with alternative disability weights, which was shown to vary results significantly, and estimates indicate a greater burden of diabetes for all countries included in this analysis.

Thirdly, the assumptions of this study are consistent with Hill et al, whose estimates suggested that $2.4 \%$ of diabetics in the US are not being treated. ${ }^{36}$ We were aware that this percentage might be different due to region-specific characteristics though.

The estimates of DALYs from this study for treated and untreated patients are pooled in a single number and further research is needed in order to estimate more specific DALYs, since diabetes is a heterogeneous disease.

Results of this study suggest that mortality due to diabetes has been postponed until older ages in most cases. While the burden of diabetes due to premature death was still significant in 2010, it is also important to remark the substantial burden of diabetes whose medical consequences lead to disability problems. Therefore, greater allocation of resources to prevent diabetes or to reduce its impact on QoL may be necessary in the upcoming years.

\section{Conclusion}

This study estimated the burden of diabetes for France, Germany, Italy, Spain, and the UK in 2010 by using the H-DALY method. The results show that Germany has the highest number of total DALYs lost, with a rate of 5.9 for 2010 in their population due to diabetes, while the UK has the lowest number of DALYs due to diabetes. With reference to the male population, diabetes health loss estimates show that Germany has the highest number of DALYs, while the UK had the lowest number of DALYs. These results are equivalent for the female population: Germany had the biggest burden measured by 9.32 DALYs due to diabetes and the UK had 4.72 DALYs, which were also the lowest compared to the other countries of interest.

Furthermore, DALYs lost to diabetes for men and women are relatively lower at younger ages and significantly increase from the 35-44 years age group in all the populations of the countries of interest. This pattern may be explained by the increasing prevalence and mortality of diabetes among the older age groups. It is worth mentioning that for all countries except for the UK, a significant increase in DALYs lost to diabetes in women is observed for the 75 years and over population, which may lead to a higher burden of diabetes for the national health system due to a higher likelihood of elderly women in developing comorbidities at these ages. 
DALYs have been increasingly cited as a powerful tool to estimate the burden of different conditions and these results could be useful for the policy making process, since DALYs seem to be a necessary measure to determine which country has the largest burden of diabetes. However, as for other measures, DALYs should not be used as a cookbook recipe to implement public policies.

\section{Disclosure}

Preliminary results of this study were presented at the 19th Annual International Meeting of the International Society for Pharmacoeconomics and Outcomes Research (ISPOR) in Montreal, QC, Canada, May 31-June 4, 2014. The authors report no conflicts of interest in this work.

\section{References}

1. Lavin N. Manual de Endocrinología y metabolismo. Philadelphia, PA: Lippincott Williams \& Wilkins; 2010.

2. World Health Organization (WHO). Global status report on noncommunicable disease 2010. Chapters 1-5. Geneva, Switzerland: World Health Organization; 2011. Available from: http://www.who.int/nmh/ publications/ncd_report2010/en/. Accessed January 18, 2015.

3. National Institute for Health and Care Excellence (NICE). Type 2 Diabetes: The Management of Type 2 Diabetes. London, UK: National Institute for Health and Care Excellence; 2009. Available at: http:// www.nice.org.uk/guidance/cg87/resources/guidance-type-2-diabetespdf. Accessed January 18, 2015.

4. Chaturvedi N. The burden of diabetes and its complications: trends and implications for intervention. Diabetes Res Clin Pract. 2007;76 Suppl 1: S3-S12.

5. International Diabetes Federation (IDF). IDF Diabetes Atlas Fact Sheets. Sixth edition. Brussels, Belgium: International Diabetes Federation; 2013. Available at: http://www.idf.org/sites/default/files/ DA6_Regional_factsheets_0.pdf. Accessed February 1, 2014.

6. Best Information through Regional Outcomes (B.I.R.O.). The Role of B.I.R.O in Implementing the Diabetes EU Policy Recommendations. A policy document by the B.I.R.O EU Project Consortium (http://www. biroproject.eu) September 2006. Perugia, Italy: Best Information through Regional Outcomes; 2006. Available from: http://www.biro-project. eu/documents/downloads/EU\%20Policy\%20Recommendations. pdf. Accessed January 18, 2015.

7. Kanavos P, van den Aardweg S, Schurer W. Diabetes Expenditure, Burden of Disease and Management in 5 EU Countries. London, UK: London School of Economics Health; 2012. Available from: http:// www.lse.ac.uk/LSEHealthAndSocialCare/research/LSEHealth/MTRG/ LSEDiabetesReport26Jan2012.pdf. Accessed February 1, 2014.

8. Devleesschauwer B, Havelaar AH, Maertens de Noordhout C, et al. DALY calculation in practice: a stepwise approach. Int J Public Health. 2014;59(3):571-574.

9. World Health Organization (WHO). The Global Burden of Disease: 2004 Update. Geneva, Switzerland: World Health Organization; 2004. Available from: http://www.who.int/healthinfo/global_burden_disease/ GBD_report_2004update_full.pdf?ua=1. Accessed October 1, 2013.

10. Fox-Rushby JA, Hanson K. Calculating and presenting disability adjusted life years (DALYs) in cost-effectiveness analysis. Health Policy Plan. 2001;16(3):326-331.

11. Hoekstra J, Hart A, Boobis A, et al. BRAFO tiered approach for benefit-risk assessment of foods. Food Chem Toxicol. 2012;50 Suppl 4: S684-S698.

12. Tijhuis MJ, de Jong N, Pohjola MV, et al. State of the art in benefit-risk analysis: food and nutrition. Food Chem Toxicol. 2012;50(1):5-25.
13. Arnesen TM, Norheim OF. Disability Adjusted Life Years: Possibilities and Problems. Available from: http://www.pitt.edu/ super7/20113001/2911.ppt. Accessed October 1, 2013.

14. European Centre for Disease Prevention and Control (ECD). Current and Future Burden of Communicable Diseases in the European Union and EEA/EFTA Countries - Methodology Protocol. Stockholm, Sweden: European Centre for Disease Prevention and Control; 2010. Available from: http://www.ecdc.europa.eu/en/publications/publications/1106_ ter_burden_of_disease.pdf. Accessed September 1, 2014.

15. Mont D. Measuring health and disability. Lancet. 2007;369(9573): 1658-1663.

16. Jenkins E. Évaluation objective de l'importance relative des maladies, des blessures et de leurs déterminants. Ottawa, Canada: Population and Public Health Branch, Health Canada; 2001.

17. Health statistics and health information systems. Metrics: DisabilityAdjusted Life Year (DALY) [webpage on the Internet]. Geneva, Switzerland: World Health Organization. Available from: http://www. who.int/healthinfo/global_burden_disease/metrics_daly/en/.Accessed November 1, 2013.

18. Schroeder SA. Incidence, prevalence, and hybrid approaches to calculating disability-adjusted life years. Popul Health Metr. 2012; 10(1):19.

19. Murray CJ, Vos T, Lozano R, et al. Disability-adjusted life years (DALYs) for 291 diseases and injuries in 21 regions, 1990-2010: a systematic analysis for the Global Burden of Disease Study 2010. Lancet. 2012;380(9859):2197-2223.

20. Institute national de la statistique et des études économiques (INSEE). Acceuil, Thèmes, Population. Available from: http://insee.fr/fr/ themes/detail.asp?reg_id=0\&ref_id=irsd2011\&page=irweb/sd2011/ dd/sd2011_population.htm. Accessed October 1, 2013.

21. DESTATIS Statistisches Bundesamt, Genesis online databank. Themen $>12$ Bevölkerung $>$ Deutschland, Stichtag, Nationalität, Geschlecht. Available from: https:/www-genesis.destatis.de/genesis/ online. Accessed October 1, 2013.

22. I.Stat: The Italian National Institute of Statistics. Browse Themes $>$ Population and Households $>$ Population $>$ Resident population on the first of January. Available from: http://dati.istat.it/Index.aspx. Accessed October 1, 2013.

23. Instituto Nacional de Estadística (INE). Proyecciones de población a corto plazo. 2010-2020. Available from: http://www.ine.es/jaxi/tabla. do? path=/t20/p269/2010-2020/10/\&file=01001.px\&type $=$ pcaxis $\& L=0$. Accessed October 1, 2013.

24. Office for National Statistics (ONS). Theme $>$ Population $>$ Data tables. Available from: http://www.ons.gov.uk/ons/. Accessed October 1, 2013.

25. Ricci $\mathrm{P}, \mathrm{Blotière} \mathrm{PO}$, Weill $\mathrm{A}$, et al. Bulletin Épidémiologique Hebdomadaire, Institut de Veille Sanitaire. 9 de November 2010 $\mathrm{n}^{\circ} 42-43$.

26. Heidemann C, Du Y, Scheidt-Nave C. Diabetes mellitus in Deutschland. Hrsg. Robert Koch-Institut Berlin. GBE kompakt 2(3). Available from: http://www.rki.de/gbe-kompakt. Accessed January 18, 2015.

27. Report Diabetes in the UK 2012.

28. NHS Scotland. Scottish Diabetes Survey 2010. Edinburgh, UK: NHS Scotland. Available from: http://bit.ly/SDS2010nhs. Accessed January 18, 2015.

29. Statistics for Wales. Welsh Health Survey 2010. Cardiff, UK: Statistical Publication Unit; 2011. Available from: http://bit.ly/WHS2010. Accessed October 1, 2013.

30. Northern Ireland Health and Social Wellbeing Survey 2005/06 [webpage on the Internet]. Belfast, UK: Central Survey Unit; 2006. Available from: http://www.csu.nisra.gov.uk/press_details.asp6.htm. Accessed October 1, 2013.

31. CépiDC Centre d'épidémiologie sur les causes médicales de décès. Interrogation des données. Indicateurs de mortalité. 2010.

32. DESTATIS StatistischesBundesamt, Genesis online databank. Themen $>$ Gesuntheitswesen $>$ Todesursachen $>$. Available from: https://wwwgenesis.destatis.de/genesis/online. Accessed September 1, 2013. 
33. I.Stat: The Italian National Institute of Statistics, Warehouse of Statistics. Available from: http://dati.istat.it/Index.aspx. Accessed September 1, 2013.

34. Instituto Nacional de Estadística (INE). Defunciones según la Causa de Muerte 2010. Resultados nacionales. Available from: http://www. ine.es $/$ jaxi $/$ menu.do? type $=$ pcaxis $\&$ file $=$ pcaxis $\&$ path $=\% 2 \mathrm{Ft} 15 \% 2 \mathrm{Fp} 41$ 7\%2F\%2Fa2010. Accessed October 1, 2013.

35. Office for National Statistics (ONS). Deaths by underlying cause: ICD10 chapter, selected causes by age and sex, 2008. Available from: http:// www.ons.gov.uk/ons/. Accessed September 1, 2013.

36. Hill SC, Miller GE, Sing M. Adults with diagnosed and untreated diabetes: who are they? How can we reach them? J Health Care Poor Underserved. 2011;22(4):1221-1238.
37. Stouthard ME, Essink-Bot ML, Bonsel GJ; Dutch Disability Weights Group. Disability weights for diseases: a modified protocol and results for a Western European region. Eur J Public Health. 2000;10(1): 24-30.

38. Mathers CD, Vos ET, Stevenson CE, Begg SJ. The burden of disease and injury in Australia. Bull World Health Organ. 2001;79(11): 1076-1084.

39. Emmanouilidou E, Galli-Tsinopoulou A, Karavatos A, NousiaArvanitakis S. Quality of life of children and adolescents with diabetes of Northern Greek origin. Hippokratia. 2008;12(3):168-175.

\section{Publish your work in this journal}

ClinicoEconomics \& Outcomes Research is an international, peerreviewed open-access journal focusing on Health Technology Assessment, Pharmacoeconomics and Outcomes Research in the areas of diagnosis, medical devices, and clinical, surgical and pharmacological intervention. The economic impact of health policy and health systems organization also constitute important areas of coverage. The manuscript management system is completely online and includes a very quick and fair peer-review system, which is all easy to use. Visit http://www.dovepress.com/testimonials.php to read real quotes from published authors.

Submit your manuscript here: http://www.dovepress.com/clinicoeconomics-and-outcomes-research-journal 